\title{
The "man-technology-environment" system in the management of transport service of construction industry
}

\author{
Ruben Kazarian ${ }^{1, *}$ \\ ${ }^{1}$ Moscow State University of Civil Engineering, Yaroslavskoe shosse, 26, Moscow, 129337, Russia
}

\begin{abstract}
In all countries, transport is considered as the basis for ensuring economic, social, military, environmental and other types of national security. It is provided more than 200 billion dollars in the US, about 200 billion dollars in Japan, more than 100 billion euros in Germany on the development of transport system. In Russia, for these purposes, is spent 1415 times less. The purpose of environmental security's transportation ensuring - protection of life and health of people, the environment, cargo and vehicles, the sustainability of transport communications and transport infrastructure in normal conditions, in emergency situations and in wartime. Man, in the process of knowing the surrounding material world, forms "speculative" (ideal) ideas about how this world is arranged and how it functions. The basis of such knowledge is intuitive or conscious modeling. The initial level of visual modeling is the multipoint representation of the object of study, so: any phenomenon, object, process, object, definition, and other elements of the conceptual layer of consciousness are put in correspondence with the "point". The further procedure of visual modeling involves the identification of all the points involved and the interrelations between them (the "logician"), this procedure will provide insight into infographic models of anthropotechnology management in the conditions of modern economic fundamentals and trends in the development of a market economy for the application of anthropotechnical management infographic models. Certification of manual labor's mechanization and transportation of construction cargo and structures (CMIT) - is one of the important construction service packages.
\end{abstract}

\section{Introduction}

High dynamics of transport provision of economic, socio-demographic and environmental safety in a market economy require the creation of a concept for the integrated use of transport in the interests of Russia's national security. In a market economy, transport, along with mechanical engineering, construction and other infrastructural components of the society, is an actual tool for solving social, economic, domestic political and foreign policy problems.

Transport is considered as an important component of the Russian economy [1], technospheric security and environmental protection [2], the object of separate certification

${ }^{*}$ Corresponding author: r.kazarian@mail.ru 
of vehicles and drivers-operators of means of mechanization and transportation, including in construction production [3].

Researchers of the problem of driving in construction consider various aspects of this multifaceted area:

- general problems of transport management, in particular - in construction [9-14, etc.];

- industrial safety in transport [4-8, etc.];

- the need and practice of certification of vehicles [15-20, etc.];

- building reconstruction of buildings, structures, quarters and other known units and conglomerations of the urban planning area [21-24, etc.].

The analysis of the listed and interrelated directions of carried out researches allows to consider that the questions of substantiation of the basic model of construction production, which is the system "man-technology-environment, TTS" and the study of the function of transport as activity in the service of control anthropotechnics, are relevant and represent Scientific and practical interest.

\section{Subject of study}

In the conditions of the reorganization of the state administration and the public formation, the change in methods and means of engineering diagnostics and monitoring, the scope of application of such a criterion significant in construction as organizational and technological reliability (OTR) has significantly expanded.

There are new directions for the development of OTR:

- organizational and economic reliability (OER);

- organizational and legal reliability (OLR), which guarantees accounting for innovations in information technologies of building rulemaking and lawmaking;

- organizational and technological flexibility and reliability (OTFR), which guarantees the most rapid response to changes in the state of construction;

- organizational and anthropotechnical reliability (OAR), which guarantees diagnostics, monitoring and ensuring the safety of production activities and human activity in the construction industry.

These new organizational forms of OTR development proved to be much more complicated than purely technical systems, since they contain human interaction with the external environment. This interaction is probabilistic, specific for each individual individual character. In this regard, for each person there is his personal norm of interaction with the external environment and adaptation to it (the adaptive norm of a particular person). The study of the specifics of the formation of the adaptive norm of a person, its manifestation and compensation of the pathologies that arise while ensuring the safety of life and productive activity of man is one of the most important tasks of science in a democratic society.

\section{Results of the study}

The increase of the OTR in optimizing the servicing subsystems of the construction industry is achieved in two ways:

- a decrease in the level of influence of factors affecting the violation of the reliability of the functioning of these subsystems (such a reduction is not always possible due to the complexity, and often the inability to influence these factors);

- the creation of subsystems that function sufficiently reliably in the presence of negative factors.

The increase in the OTR of the servicing subsystems of construction production is effected by a decrease in the level of influence of pathogenic factors by combining these two 
directions, as well as by improving the "operator-workplace" system. In the comparative analysis of the quality and comfort of closed mobile workplaces (CMW) of cabins of various modifications of vehicles for mechanization of construction production, the Ural Automotive Plant and UralSpetstechnika, a technique and an automated technology for rapid quality assurance of the CMW were developed and tested at the enterprises. Monitoring the parameters of the system "man-technology-environment, MTE" in the construction industry [Chulkov V.O., 2005]. The use of such computer information technology in the process of monitoring the parameters of construction production, as a MTE system, allows to increase the comfort and productivity of a worker.

In order to emphasize the relevance and significance of the applied directions of harmonization of the system of the MTE system, we introduce a number of initial definitions and concepts.

The MTE system is a basic infographic model of the statics and dynamics of the state of any situational-sensual (ideal, spiritual, energy-informational, etc.) and subject-material compositions, the indispensable component of which is a person working productively in his environment.

Technique is not a set of (diverse) products of thought activity and man's production activity (information, documents, books and other printed publications, software products, machines and mechanisms, buildings and structures, works of culture and art, etc.) that do not exist in nature.

The environment is a collective term that includes the concepts of the natural environment (natural, non-miraculous, formed in itself all living things, including humans, and its supporting existence) and the non-natural environment (artificial, technogenic, created as a result of man's thought activity and production activity and exploited exclusively by him For their own needs).

Anthropotechnics is a scientific and practical direction designed to harmonize the MTE system at various levels of its complexity (from one individual to the whole of mankind) on the basis of models, algorithms and technologies for the formation of compatible organizational structures for human activities.

Infographics is a scientific and practical line of thought activity and production activity designed to promote harmonious understanding and co-organization of individuals and communities on the basis of intensive development of figurative thinking and the use of visual (visually perceived) forms of modeling (objectified and founded by Chulkov V.O. in 1966).

Harmonization of the device, functioning, set of solved tasks or activities in relation to the MTE system - mutual agreement, establishment of balance, harmony, balance between problems and tasks of a similar priority level (equally requiring implementation in a given period), coordination, streamlining, Each of the components of the TTS system and in the system as a whole. Harmonization is carried out by a deliberately controlled distribution between the components of the TTS system of limited resources by priority.

Priorities are the criteria that influence the definition of the relative importance of problems and tasks, and the elimination of existing "conflicts of interest" arising from the limited resources.

At the end of the twentieth century, Academician Sudakov K.V. suggested the possibility of identifying three directions for the development of the theory of functional systems.

The first direction is general philosophical and methodological research that establishes as a result of theoretical search a "conceptual bridge" between the concept "functional system" (as a scientific and philosophical category) and its application to a specific object under study (Anokhin P.K., Sudakov K.V., their disciples and followers). The task of this direction is to make the theory of functional systems sufficiently formalized and applicable 
for the purpose of improving the cognitive process in subject areas by systematizing and generalizing empirical data, i.e. Turn it into an instrument of applied scientific research.

The second direction is the study of functional systems that actually exist in biology, physiology, physics, medicine, sociology, economics and other scientific and practical areas of human functioning and activity. The listing of numerous outstanding researchers in this field within the framework of the article seems inexpedient. The task of this direction is to overcome the narrow analytical approach in research work with the help of the first direction of the development of the theory of functional systems and to lay a "conceptual bridge" between synthetic and analytical approaches in research.

The third direction is the mathematical formalization of the concept of a functional system as an organic component of the mathematical theory of systems (Mesarovich M.D., etc.). Until recently, this trend declared an unshakable principle. First, on a purely theoretical basis, a mathematical model is formulated and only then, proceeding from it, explain the real properties and manifestations of any system (including biological, physical, technical, social, industrial, economic, etc.), including the functional one. That is, according to the supporters of this trend, theoretical mathematical modeling must precede applied research.

However, there is also the opposite view: true system regularities can be identified only as a result of applied research in biology, physiology, physics, engineering, and also in the study of "large" socio-economic and production systems. According to many founders of the domestic systemic movement (Kantorovich L.V., Buslenko N.P., Moiseyev N.N., Anokhin P.K., Sudakov K.V., Kuzin L.T., etc.) this material should be the basis of mathematical analysis and strict formalization of system regularities.

The emergence and rapid development of technical systems and the technical sciences that study them, which had no place in the structure of the classification of the natural sciences of Aristotle and are the product of man's thought activity and production activity (in contrast to the natural sciences, where man studies and ascertains the phenomena and laws of nature as his natural habitat ), changed the focus and shifted attention to the initial stages of choosing and justifying the goals, their usefulness, the conditions of implementation, the links with previous processes.

\section{Discussion}

The basic infographic model of the technical field of knowledge, as mentioned above, is the MTE system. The main thing was the identification of the mechanism of functioning of the MTE system and the normal functioning of the conditions that violate it.

The mechanism of operation of the MTE includes:

- research of system functions;

- determination of the relationships of each function with the set of interacting elements of the MTE system;

- consideration of the structure of the system not as a relationship (interrelation, interaction), but as a definite arrangement of some elements of the MTE system relative to others (relations between relations).

Knowledge of the structure and functions of the MTE system is important, but not sufficient for effective problem solving. It is necessary to correlate the goals of the subjectperson (the MTE system component) with the complex of goals of the MTE system as a single functioning entity and to find out how the implementation of the objectives of the subject-person affects the functioning of the MTE system. In the same way, it should be correlated with the objectives of the entire MTE system and the goal of its other two components - technology and environment. The formation of a consensus of all these goals, or rational situations close to such a consensus, represents an important practical result of harmonizing the structure of the MTE system. 
MTE systems are explored in three directions:

- $\quad$ systemology (theory of MTE systems);

- system engineering (practice of functioning of MTE systems);

- system analysis (methodology for the future development of MTE systems).

The last of these directions needs comment.

Initially, the analysis of MTE systems was understood as a complex forecast based on mathematical modeling. The results of the real practice of system engineering led to the conclusion that mathematics is ineffective in analyzing the wide problems with a lot of uncertainties that are characteristic for research and development of the MTE technique and system as a single whole. Therefore, they formed the concept of such a system analysis, in which the emphasis is mainly on the development of new dialectical scientific principles of logical and information-energy research of MTE systems and its components, taking into account their interrelations and conflicting trends. With this approach, not the mathematical methods but the logic of system analysis and the ordering of decision-making procedures are brought to the fore, understanding by system approach a certain set of system principles and concepts, in which, besides the generally accepted, there must necessarily be innovative ones. For example, instrument-computer diagnostics and monitoring of the MTE system as a whole and its components (Chulkov G.O., Chulkov V.O., Masturov I.Ya., etc.), complex qualimetric assessment of the level of human comfort in stationary and mobile habitats (Chulkov V.O., Griff M.I., Burianov P.D., Kazaryan R.R., etc.), complex life safety and human productive activity in the TTS system (Lyubimov M.M., Mokhov A.I., etc.), homeostat of building objects (Volkov A.A., Telichenko V.I., Shulzhenko S.N., etc.). A lot of innovative principles and perceptions about the MTE system remain constantly open.

Any principle or concept of the MTE system (generalization) has its own field of applicability, within which they will be correct, and outside this area may turn out to be incorrect. This is one of the fundamental characteristics of infographics - the positional perception. Many problems arise because they use the model not where it can work (that is, at another position).

At present, the heads of the enterprises of construction mechanization and transportation question the need for conducting diagnostic work. They are motivated by the fact that with a high load of means of mechanization and transportation, it seems likely that it is problematic to stop it and withdraw it from the construction process for diagnostic and maintenance purposes. Most likely, this paradox is associated with the shortsightedness of such leaders, forgetting that the means of mechanization and transportation brings revenue when it is guaranteed to work.

The practice of exploiting transport means to failure, which has taken deep roots and becomes a real problem for the construction industry, is puzzling. This situation is generated by the elementary illiteracy of the owners of equipment. In the near future, this situation is unlikely to change.

The client must have confidence that the company that produces a specific means of transportation will work for at least a decade, and will honestly and conscientiously fulfill its obligations for service. And the service company should have a serious client base, it is necessary to keep the minimum prices, have a supply service, highly qualified personnel and all this with a high quality of services. At the moment, there are no such enterprises on the market of the construction industry of the Russian Federation. The market for supply, service and repair services is relatively young, and it's too early to talk about the quality of its players. The issue of the manufacture of works on technical inspections and repairs of transport equipment on its own or by the involved enterprises, has recently generated a lot of opinions. It is believed that it is better to completely abandon own repair services, making payment for repair services from time to time and as necessary, and not bear the burden of owning underloaded production facilities. Someone, on the contrary, tends to economize at high rates 
of service enterprises, doubting (often - quite justifiably) as their work. In the Soviet era, manufacturers of domestic means of mechanization and transportation determined the timing of their capital repairs in the factory documentation. Foreign manufacturers of such equipment do not consider repair issues at all. Firstly, it is not profitable for them, and secondly, in most cases it is not profitable for the owner of equipment.

For many domestic enterprises at the moment, the overhaul of machinery is the only visible opportunity to somehow maintain its own fleet of vehicles due to lack of funds to purchase new cars. In all cases, major repairs are carried out in conditions other than a conveyor assembly, even if it is carried out by the manufacturer. In the process of overhaul it is necessary to restore from 40 to $70 \%$ of the total volume of the technical means of transportation. Modern construction production is characterized by complex technological processes, a large capacity of the means of transportation used, their high productivity, complex devices for monitoring and controlling technological processes, dangerous consequences of accidents. These features lead to high costs of equipment downtime.

Achievement of organizational and technological reliability of the joint venture requires expensive maintenance programs, as well as reliable, and therefore more expensive equipment. Any system or method of detecting malfunctions that allows the vehicle to be used without downtime, contributes to the intensification of production and the reduction of operating costs, deserves the closest attention. The detection and elimination of malfunctions of technological construction equipment has a very significant economic significance in the organization of construction production at various facilities.

\section{Conclusions}

1. Among the objectives of our study:

a. at the level of model experiments of the reconstructed system, to predict the level of comfort of labor activity, and in the long run and human life as an accentuated component of the MTE system;

b. reduce the risk of pathogenic exposures and emergencies in the MTE system that are not predicted by statistical methods, by pre-diagnosing, monitoring, and taking adequate adequate decisions based on their results.

2. In the future, the above-mentioned areas of research will allow creating an appropriate array of average regulatory data that can be formalized in the form of officially approved regulatory documents that provide the possibility of their application in the provision of certification services, with the subsequent development of elements of a new model for certification of the MTE system.

3. The development of an appropriate regulatory framework using the results of engineering express diagnostics in assessing the quality of industrial and public mobile habitats will ensure the creation of fundamentally new standards in the provision of certification services for the transport complex of construction production.

4. It is advisable to use the certification of mechanization and transportation means in the construction industry as a tool to improve the safety and quality of transport services provided, protect the rights of consumers of transport services, improve the competitiveness of producers (sellers) of transport industry products and service providers. The main advantage of having a certificate is the public recognition of the high quality of the services provided. It is important to note that this approach is universal, that is, it can be applied to any version of the practical implementation of the "mantechnology-environment, MTE" system, in which a person is always a priority component. 


\section{References}

1. N.V. Akindinova, Ya.I. Kuzminov, E.G. Yasin, Voprosy ekonomiki, 6 (2016)

2. An. Mottaeva, V. Lukinov, As. Mottaeva, Strategy of management of the state and municipal ownership: theory and practice (Moscow, MGSU, 2015)

3. R.R. Kazaryan, V.O. Chulkov, International collection of scientific papers (MGAKHiS, Moscow, 2012)

4. T.V. Zyuba, Industrial safety in transport. Tutorial (Academy of Civil Aviation, SPb 2004)

5. An. Mottaeva, As. Mottaeva, Economy and entrepreneurship 3-2(56-2), 98-102 (2015)

6. B.A. Levin, E.A. Mamaev, The World of Transport, 1 (2005)

7. B.A. Levin, Business Premier, 1-2 (2014)

8. A.N. Lieberman, Technogenic safety: the human factor (New Century, St. Petersburg, 2006)

9. Yu.A. Tagiltseva, Concept 11, 3881-3885 (2016)

10. S.V. Ilinova, Increase of economic efficiency of ecological safety of transport system, The Engineering bulletin of Don Transport (2010)

11. A. Boykov, An. Mottaeva, Economy and entrepreneurship 11-2(52-2), 174-178 (2014)

12. K.V. Sudakov, V.O. Chulcov, R.R. Kazaryan, et. al. Antropotechnics: Norm in every living thing and artificial beings (SvR-ARGUS, Moscow, 2013)

13. K.A Kirsanov, O.A. Bogomolov, Transport revolutions and their consequences, Internetjournal "Naukovedenie" (2011)

14. An. Mottaeva, As. Mottaeva, Economy and entrepreneurship 3-2(56-2), 98-102 (2015)

15. R.R. Kazaryan, Natural and technical sciences, 6(84) (2015)

16. An. Mottaeva, V. Lukinov, As. Mottaeva, Economy and entrepreneurship 8(49), 34-37 (2014)

17. V.O. Chulkov, O.N. Kuzina, Management of investment and construction and housing and communal services: International collection of scientific papers (Moscow, 2010)

18. A.A. Lapidus, Technology and organization of construction production, 1 (2012)

19. E. Vasilyeva, I. Polyakova, Economics and Entrepreneurship 4-2(81-2), 1024-1028 (2017)

20. R.R. Kazaryan, V.O. Chulkov, International collection of scientific papers (MGAKHiS, Moscow, 2012)

21. E.V. Kaznacheeva, Management in conditions of uncertainty (Higher School of Economics, Moscow, 2014

22. V.O. Chulkov, M.S. Kiselev, Vestnik MGSU, 3 (2007)

23. V.O. Chulkov, P.D. Buryanov, V.V. Shmakov, Industrial and civil construction, 10 (2005)

24. B.A. Lyovin, The World of Transport, 1 (2012) 